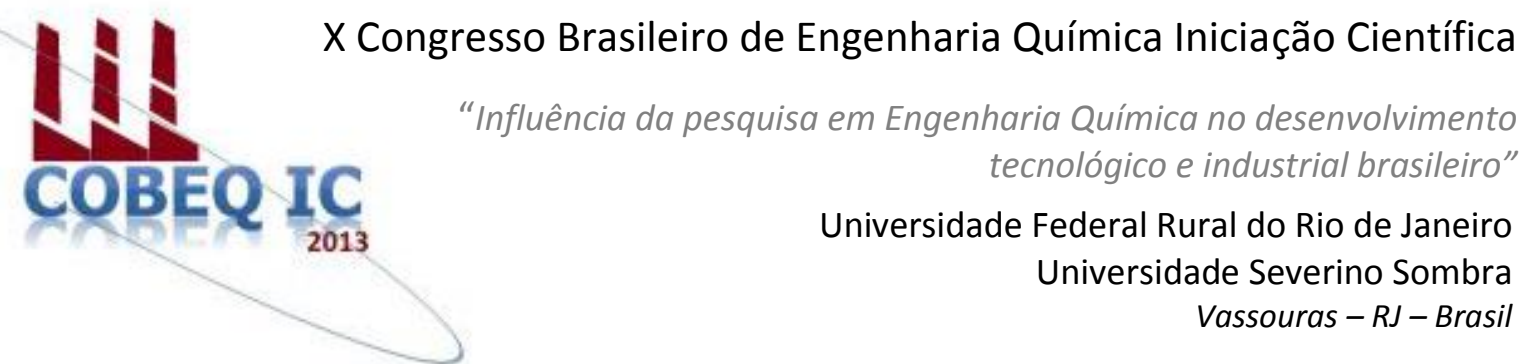

\title{
UTILIZAÇÃO DO RESÍDUO DO PROCESSO DE DESCAROÇAMENTO DA AZEITONA NO TRATAMENTO DE EFLUENTE
}

\section{C.R. SIMÕES ${ }^{1}$; C. HERTEL ${ }^{2}$; D.M. TORRES ${ }^{3}$; A. R. PEREIRA ${ }^{4}$; M.R.F. NETO ${ }^{5}$, C.S.S. PEREIRA $^{6}$}

\author{
${ }^{(1)}$ Discente em Engenharia Ambiental - USS; ${ }^{(2)}$ Discente em Química Industrial - USS; ${ }^{(3)}$ \\ Mestrando em Engenharia de Materiais - PUC/RIO; ${ }^{(4)}$ Doutorando TPQB/EQ/UFRJ; ${ }^{(4,5)}$ \\ Docente - CECETEN/USS \\ Centro de Ciências Exatas, Tecnológicas e da Natureza - USS, \\ Avenida Expedicionário Osvaldo de Almeida Ramos, 280 - Vassouras, RJ - CEP 27700-000 \\ e-mail: crispereirauss@gmail.com
}

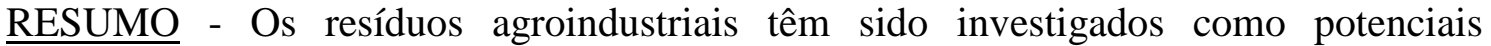
adsorventes em efluentes aquosos devido a sua capacidade de sorção. A indústria de extração de azeite gera grandes quantidades de subprodutos dentre eles uma grande quantidade de caroço oriundo da etapa de descaroçamento da azeitona. Neste trabalho avaliou-se a utilização do caroço de azeitona como um sorvente natural e de baixo custo no tratamento de efluente na própria indústria de processamento de azeitonas. $\mathrm{O}$ efluente bruto e o efluente tratado foram caracterizados com relação aos valores de demanda química de oxigênio (DQO), pH, turbidez e óleos e graxas (TOG). As análises permitiram avaliar que o caroço de azeitona em pó associado com o sistema de flotação apresentou uma redução dos valores dos parâmetros analisados.
\end{abstract}

Palavras-chave: flotação, bioadsorção, azeitona

\section{INTRODUÇÃO}

De acordo com ROSA (2002), a poluição industrial vem sofrendo um aumento, e isso têm levado os órgãos de controle ambiental a estabelecer limites mais rigorosos de efluentes industriais. E, com isso, as empresas acabam sendo obrigadas a melhorar seus sistemas de tratamento de efluentes utilizando novas tecnologias.

A flotação por ar dissolvido é uma técnica onde o ar é dissolvido em água a altas pressões em uma câmara de saturação. Ao sair da câmara de saturação, o ar dissolvido forma micro-bolhas devido à diferença de pressão do interior da câmara de saturação e a pressão atmosférica (exterior). Essas micro-bolhas se juntam às partículas de impureza, diminuindo a sua densidade fazendo com que as partículas fiquem suspensas. Desta forma, os flocos aderem-se às bolhas e são transportados até a superfície da câmara, onde são removidos mecanicamente (Dezotti, 2008 e Martins, 2009).

Um dos principais processos da indústria geradora do efluente analisado é o descaroçamento de azeitonas, gerando uma grande quantidade de resíduo (conforme 
Figura 1), que representa $25 \%$ do peso total inicial da azeitona.

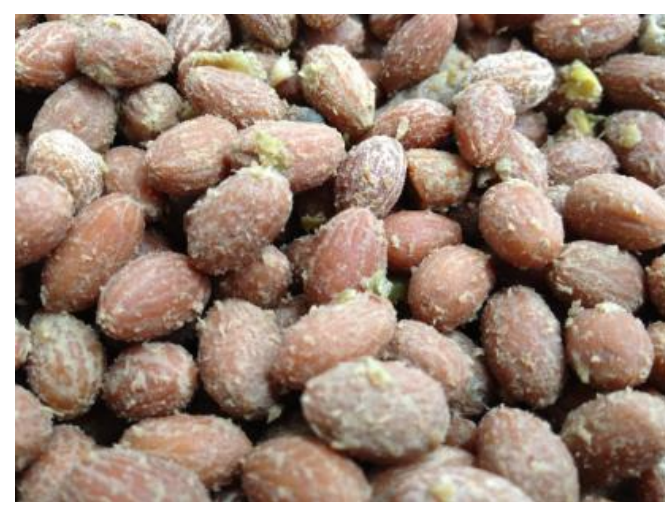

\section{Figura 1 - Caroços de azeitona após o processo de descaroçamento}

De acordo com os dados da empresa, a máquina em sua capacidade de produção, pode processar em média 19.000,00 Kg de azeitonas inteiras (com 4 maquinas em operação), gerando $4.750,00 \mathrm{~kg}$ do residual acima. Porém a quantidade de polpa de azeitona ainda presente nos caroços pode variar de 20 a $25 \%$ do peso total do resíduo, onde considerando o menor rendimento, dentro do valor gerado média/dia, pode-se obter uma quantidade média de $950,00 \mathrm{~kg}$ de polpa de azeitona e $3.800,00 \mathrm{~kg}$ de caroços já limpos (após processo de despolpamento). A partir destes dados, é possível avaliar a grande quantidade de resíduo gerado neste processo. Considerando 26 dias de trabalho, pode-se gerar a quantidade de $123.500,00 \mathrm{~kg}$ de resíduo (Chimatti, 2012).

Segundo Germán Tenorio Rivas, os caroços de azeitona são excelentes instrumentos para a depuração de água contaminada por metais pesados como cromo e que a capacidade de absorver este metal pesado, reside na diferença de carga elétrica e em uma atração iônica.

Rodriguez et al (2008), mostra que o caroço de azeitona foi utilizado como um adsorvente sólido para a remoção de íons metálicos de efluentes aquosos, determinando o efeito de alguns parâmetros na sorção de $\mathrm{Cd}$ (II), $\mathrm{Pb}$ (II), $\mathrm{Ni}$ (II) e $\mathrm{Cu}$ (II).

O objetivo do trabalho foi avaliar a utilização deste resíduo na tratabilidade do efluente em estudo.

\section{MATERIAIS E MÉTODOS}

A pesquisa foi realizada no Laboratório de Química Ambiental da Universidade Severino Sombra (USS) onde foram conduzidos os ensaios de coagulação, floculação e flotação do efluente oriundo de uma indústria de processamento de alimentos.

\section{Caracterizações do efluente}

O efluente utilizado foi cedido por uma indústria de alimentos localizada na cidade de Três Rios/RJ. O efluente bruto foi coletado após o tanque de equalização da estação de tratamento de efluentes. $\mathrm{O}$ efluente foi armazenado em um recipiente de PVC de 5L e mantido refrigerado até posterior análise.

$\mathrm{O}$ efluente bruto foi caracterizado com relação aos parâmetros de $\mathrm{pH}$, Ferro total, sílica, zinco, fosfato, turbidez, DQO e TOG. As análises dos metais foram realizadas no laboratório de uma indústria siderúrgica: em um erlenmyer de $150 \mathrm{ml}$, foram adicionados $50 \mathrm{ml}$ da amostra do efluente e $5 \mathrm{ml}$ de ácido nítrico e posterior aquecimento em uma chapa elétrica de $150^{\circ} \mathrm{C}$ até redução de $5 \mathrm{~mL}$ do volume. Após esta etapa, foram adicionados 5 $\mathrm{mL}$ de ácido nítrico e novamente aquecidos até a redução de $3 \mathrm{ml}$. Após esfriamento, a amostra foi transferida para um balão de $50 \mathrm{ml}$ e avolumada até o menisco. A análise foi realizada por ICP (Plasma Indutivamente Aclopado), e os outros parâmetros foi de acordo com as metodologias do Standard Methods for the Examination of Water and Wastewater. A turbidez do efluente foi medida em um turbidímetro da Policontrol.

\section{Ensaios de Coagulação/Floculação e Sedimentação}

Os ensaios de coagulação/floculação foram realizados em Jar Test e objetivaram a determinação do melhor $\mathrm{pH}$, melhor dosagem do caroço de azeitona moído e melhor tempo de floculação, alcançando deste modo, a otimização dos parâmetros de tratabilidade para o efluente em estudo.

Os experimentos foram realizados com $300 \mathrm{~mL}$ de efluente variando o $\mathrm{pH}$ de 5 a 9. 
Para a correção do $\mathrm{pH}$ foram utilizadas soluções de acido sulfúrico e hidróxido de sódio $50 \%$. Após a avaliação do $\mathrm{pH}$, foi realizado um primeiro ensaio utilizando 750 mg do caroço de azeitona por litro de efluente. Os ensaios procederam Jar Test com velocidade de $100 \mathrm{rpm}$ durante 5 minutos (mistura rápida) e depois velocidade de $30 \mathrm{rpm}$ durante 30 minutos (mistura lenta). Foi realizado o teste de turbidez em todas as amostras para identificar o $\mathrm{pH}$ ideal.

Foram testadas cinco concentrações do caroço moído que variaram de $1500 \mathrm{mg} / \mathrm{L}$ a $3500 \mathrm{mg} / \mathrm{L}$. O tempo de decantação foi avaliado em 20, 25, 30, 35 e 40 minutos. Todos os testes foram realizados em duplicata.

Definidas as condições ideais de tratamento do efluente, foi realizada a técnica de flotação por ar dissolvido, com pressão de 3 bar e razão de refluxo de $50 \%$.

\section{RESULTADOS E DISCUSSÕES}

Os resultados das análises de caracterização físico-química do efluente bruto da indústria de alimentos estão representados na Tabela 1.

Tabela 1 - Caracterização físico-química do efluente.

\begin{tabular}{lc}
\hline Parâmetros: & Valores \\
Temperatura & $25^{\circ} \mathrm{C}$ \\
pH & 3,5 \\
Turbidez & $805 \mathrm{NTU}$ \\
DQO & $6.312 \mathrm{mg} / \mathrm{L}$ \\
TOG & $14200 \mathrm{mg} / \mathrm{L}$ \\
Fe total & $2,33 \mathrm{ppm}$ \\
Fosfato & $27,20 \mathrm{ppm}$ \\
Sílica & $4,76 \mathrm{ppm}$ \\
Zinco & $0,24 \mathrm{ppm}$ \\
\hline
\end{tabular}

\section{Ensaios de coagulação e floculação}

Analisandos os dados obtidos na Figura 2 , observa-se que o efluente com $\mathrm{pH} 5$ foi o que apresentou a menor turbidez $(411,75$ NTU). Este valor de $\mathrm{pH}$ foi utilizado nos ensaios posteriores.

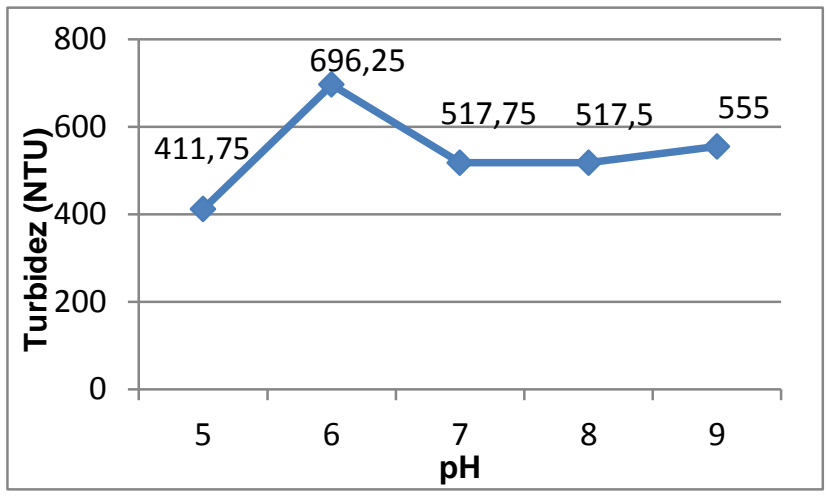

Figura 2 - Variação da turbidez em diferentes valores de $\mathbf{p H}$

\section{Ensaios da concentração ideal do caroço de azeitona}

Foram realizados ensaios para a concentração ideal do caroço de azeitona. Os resultados obtidos podem ser analisados através da Figura 3.

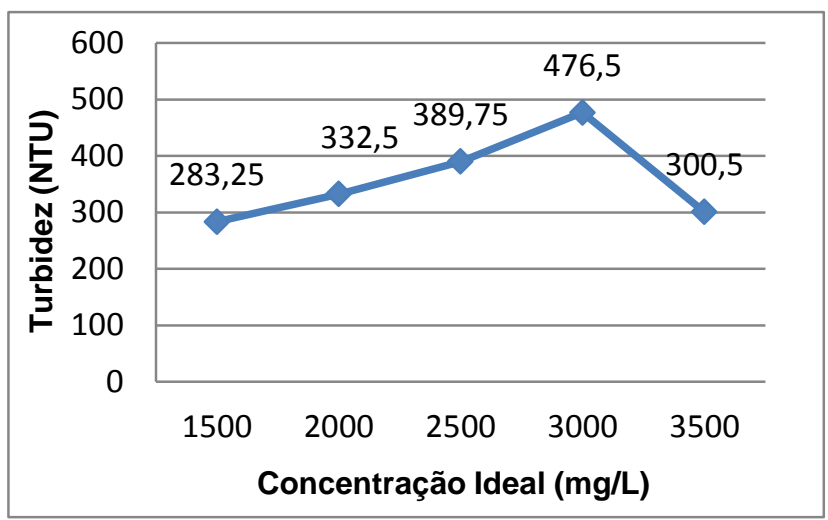

Figura 3 - Variação da turbidez em diferentes concentrações de pó do caroço de azeitona

A partir do gráfico da Figura 3, a menor turbidez obtida foi 283,25 NTU e a concentração ideal do caroço de azeitona de $1500 \mathrm{mg} / \mathrm{L}$.

\section{Tempo de decantação}

De posse do melhor $\mathrm{pH}$ e da melhor concentração do caroço de azeitona, avaliou-se o tempo de decantação do tratamento, conforme mostra a Figura 4. 


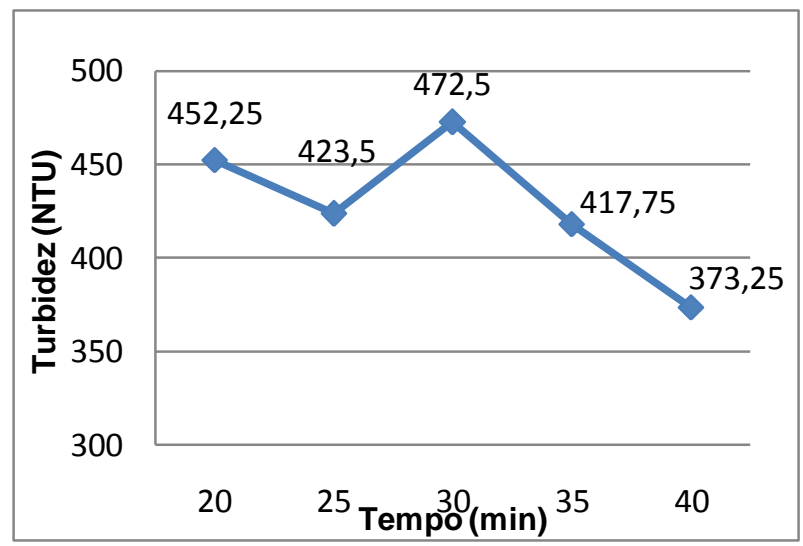

Figura 4 - Variação da turbidez com o tempo de decantação

Pode-se observar que a menor turbidez (373,25 NTU) foi obtida para o tempo de decantação de 40 minutos.

A Tabela 2 apresenta os dados do efluente bruto e os dados do efluente tratado com as condições ideais do adsorvente associado com o sistema de flotação por ar dissolvido.

\section{Tabela 2 - Comparação do efluente bruto} com o efluente tratado

\begin{tabular}{lccc}
\hline Parâmetros & $\begin{array}{c}\text { Efluente } \\
\text { Bruto }\end{array}$ & $\begin{array}{c}\text { Efluente } \\
\text { Tratado }\end{array}$ & $\begin{array}{c}\text { Parâmetros de } \\
\text { lançamento de } \\
\text { acordo com a } \\
\text { legislação }\end{array}$ \\
\hline pH & 3,506 & 5,078 & 5 a 9 \\
Turbidez & 805,0 & 238,5 & - \\
NTU & & & \\
TOG & 14200 & 1900 & $50 \mathrm{mg} / \mathrm{L}$ \\
(mg/L) & & & \\
Fe Total & 2,33 & 0,73 & - \\
ppm & & & \\
Fosfato ppm & 27,20 & 36,11 & - \\
Sílica ppm & 4,76 & 10,13 & - \\
Zinco ppm & 0,24 & 0,16 & $5,0 \mathrm{mg} / \mathrm{L}$ \\
\hline DQO ppm & 6312,4 & 4407,6 & - \\
\hline
\end{tabular}

Analisando os dados obtidos, o efluente tratado apresentou redução nos parâmetros: óleos e graxas, Fe total, zinco e DQO. O mesmo não foi constatado com os dados relacionados ao fosfato e sílica. $\mathrm{O}$ parâmetro relacionado à DQO apresentou redução de aproximadamente $30 \%$ após o tratamento.

Segundo a resolução CONAMA 357/05 e a 430/2011 o padrão de lançamento para o pH do efluente é de 5 a 9 . O efluente tratado se enquadrou na legislação brasileira, apresentando o pH 5. O parâmetro relacionado ao teor de óleos e graxas, apesar de apresentar uma redução de significativa de aproximadamente $87 \%$ ainda não se enquadrou nos parâmetro da legislação, já que o valor permissível de óleos e graxas oriundos de óleos vegetais ou gordura animal é de no máximo $50 \mathrm{mg} / \mathrm{L}$.

\section{CONCLUSÕES}

O mercado nacional é crescente em azeitonas e azeite de oliva, por isso, são de extrema importância que sejam desenvolvidas tecnologias para o manejo racional dos resíduos desta indústria de maneira sustentável. O pó do caroço da azeitona tem propriedades de bioadsorção, podendo representar uma alternativa para tratamento de efluentes de indústrias alimentícia.

\section{REFERÊNCIAS}

CHIMATTI, W. (2012) Fabricação de Subprodutos Gerados a partir do Resíduo do Processo de Descaroçamento e Seleção de Azeitonas Brutas. Monografia (Graduação) - Universidade Severino Sombra, Vassouras - RJ.

DEZOTTI, M., BASSIN, J.P., BILA, D.M., (2008), Processos e técnicas para o controle ambiental de efluentes líquidos. $1^{a}$ Edição, E-papers, Rio de Janeiro.

MARTINS, A. L. S. (2009) Remoção de Chumbo e Bário de um Efluente Aquoso via Flotação por Ar Dissolvido. Dissertação (Mestrado) - Universidade Federal Rural do Rio de Janeiro, SEROPÉDICA-RJ.

RODRÍGUEZ G.(2008), Lama A., Rodríguez R., Jiménez A., Guillén R., FernándezBolaño J.: "Olive stone an attractive 
source of bioactive and valuable compounds." Bioresource Technology, 99, 5261.

RIVAS, G. "Resíduos de azeitona ajudam a tratar efluentes". Revista Atualidades. Disponível em http://www.quimica.com.br/revista/qd46 7/atual/atualidades04.html. Acesso em 12 junho 2013.

\section{AGRADECIMENTOS}

Os autores agradecem a USS, a FUNADESP, PIBIC-USS pela bolsa de IC e a parceria das empresas SWM INTL e AQUAFLOT INDUSTRIAL, responsáveis pelo fornecimento da Unidade de Flotação por Ar Dissolvido. 